Fetal Diagnosis and Therapy
Fetal Diagn Ther 2018;44:112-123

DOI: $10.1159 / 000479684$
Received: March 30, 2017

Accepted after revision: July 19, 2017

Published online: September 20, 2017

\title{
A Low Cerebroplacental Ratio at 20-24 Weeks of Gestation Can Predict Reduced Fetal Size Later in Pregnancy or at Birth
}

\author{
Edgar Hernandez-Andrade ${ }^{a, b}$ Eli Maymon ${ }^{a, b}$ Offer Erez ${ }^{a, b}$ Homam Saker $^{a, b}$ \\ Suchaya Luewan ${ }^{a-c}$ Maynor Garcia ${ }^{a, b}$ Hyunyoung Ahn ${ }^{a, b}$ Adi L. Tarca ${ }^{a, b}$ \\ Bogdan Done $^{a}$ Steven J. Korzeniewski ${ }^{a, b, d}$ Sonia S. Hassan ${ }^{a, b}$ \\ Roberto Romero ${ }^{a, d-f}$
}

\begin{abstract}
aPerinatology Research Branch, NICHD/NIH/DHHS, Bethesda, MD and Detroit, MI, and bepartment of Obstetrics and Gynecology, Wayne State University School of Medicine, Detroit, MI, USA; ' $D e p a r t m e n t$ of Obstetrics and Gynecology, Chiang Mai University, Chiang Mai, Thailand; d Department of Epidemiology and Biostatistics, Michigan State University, East Lansing, MI, e Department of Obstetrics and Gynecology, University of Michigan, Ann Arbor, MI, and ${ }^{\mathrm{f} C e n t e r}$ for Molecular Medicine and Genetics, Wayne State University, Detroit, MI, USA
\end{abstract}

\section{Keywords}

Adverse perinatal outcome - Birthweight - Doppler · Fetal growth restriction - Middle cerebral artery - Umbilical artery . Uterine arteries

\begin{abstract}
Aim: To determine whether Doppler evaluation at 20-24 weeks of gestation can predict reduced fetal size later in pregnancy or at birth. Methods: Fetal biometry and Doppler velocimetry were performed in 2,986 women with a singleton pregnancy at 20-24 weeks of gestation. Predictive performances of the umbilical artery pulsatility index (UA-PI) or the mean uterine artery pulsatility index (UtA-PI) $>95$ th percentile, middle cerebral artery pulsatility index, or cerebroplacental ratio $(C P R)<5$ th percentile for early small for gestational age (SGA; $<34$ weeks of gestation), late SGA ( $\geq 34$ weeks of gestation), or SGA at birth (birthweight $<10$ th percentile) were analyzed. Results: The prevalence of early SGA, late SGA, and SGA at birth was $1.1,9.6$, and $14.7 \%$, respectively. A CPR $<5$ th percentile had a positive likelihood ratio
\end{abstract}

$(\mathrm{LR}+)$ of 8.2 (95\% confidence interval [Cl] 5.7-12.0) for early SGA, a LR+ of $1.6(95 \% \mathrm{Cl} 1.1-1.2)$ for late SGA, and a LR+ of 1.9 (95\% Cl 1.4-2.6) for SGA at birth. A UtA-PI >95th percentile was associated with late SGA and SGA at birth, while an UA-PI >95th percentile was associated with early SGA. Associations were higher in fetuses with an estimated fetal weight $<10$ th percentile. Conclusion: Fetal biometry and Doppler evaluation at 20-24 weeks of gestation can predict early and late SGA as well as SGA at birth.

(c) 2017 S. Karger AG, Basel

\section{Introduction}

The potential of fetal growth can be affected by a hostile uterine environment that may be associated with a chronic reduction of the oxygen and nutrient supplies and will eventually be reflected in a low estimated fetal weight (EFW) [1-4]. The fetal hemodynamic response to these conditions is adaptive in nature and prioritizes an optimal supply of oxygen to the brain, heart, and adrenal

\section{KARGER}

(C) 2017 S. Karger AG, Basel

E-Mail karger@karger.com

www.karger.com/fdt
Roberto Romero, MD, D Med Sci, or Edgar Hernandez-Andrade, MD, PhD

Perinatology Research Branch, NICHD/NIH/DHHS

Wayne State University / Hutzel Women's Hospital

3990 John R, 4 Brush, Detroit, MI 48201 (USA)

E-Mail prbchiefstaff@med.wayne.edu or ehernand@med.wayne.edu 
glands at the expense of muscle, bone, and fat tissue [512]. Therefore, fetal hemodynamic changes might be present prior to the reduced size of biometric parameters such as abdominal and head circumferences and femur length.

In fetuses already considered small for gestational age (SGA; EFW <10th percentile), an abnormal Doppler velocimetry of the umbilical artery (UA) or of the middle cerebral artery (MCA) has been associated with low $\mathrm{pO}_{2}$ in umbilical cord blood [13], increased prevalence of cesarean deliveries for nonreassuring fetal status [14], low Apgar scores, admission to the neonatal intensive care unit, and long-term neurological complications [15-19]. Fetuses with an EFW $<10$ th percentile and absent or reversed end-diastolic velocities in the UA have a $45-70 \%$ increased risk of perinatal death [20]. Therefore, Doppler evaluation of SGA fetuses can contribute to the characterization of the severity of the hypoxic insult, the identification of the optimal time for delivery, and reduction in the prevalence of perinatal mortality and morbidity [2123].

Currently, however, Doppler studies are not recommended for fetuses with a normal EFW $[24,25]$. The Cochrane Database of Systematic Reviews reported that there is still no clear evidence that a fetal Doppler examination of low-risk pregnant women can reduce the prevalence of fetal mortality/morbidity [25]. Similarly, fetal Doppler evaluation has not been recommended before the suggested time for normal or reduced fetal growth screening at 24 weeks of gestation [26]. Recently, De Paco et al. [27] explored the association between abnormal Doppler parameters obtained at 19-22 weeks of gestation and perinatal complications. The authors reported a 3.5 increment in the risk (95\% confidence interval [CI] 1.77.1) of birthweight $<5$ th percentile in the presence of an abnormal umbilical artery pulsatility index (UA-PI) $>90$ th percentile. These results suggest that early Doppler fetal evaluation might contribute to the identification of fetuses at risk of reduced growth. In this study, we determined the diagnostic performance of fetal and uterine Doppler parameters at 20-24 weeks of gestation to detect fetuses who will show a reduction of size later in pregnancy or at birth.

\section{Methods}

Characteristics of the Study Population and Study Design

This cohort study was conducted at the Center for Advanced Obstetrical Care and Research (CAOCR), Perinatology Research Branch of the Eunice Kennedy Shriver National Institute of Child
Health and Human Development, National Institutes of Health, U.S. Department of Health and Human Services (NICHD/NIH/ DHHS), Wayne State University School of Medicine, and Hutzel Women's Hospital, Detroit, MI, USA. All patients provided written informed consent for ultrasound examinations and were enrolled in research protocols approved by the Human Investigation Committee of Wayne State University and by the Institutional Review Board of NICHD.

Our cohort included 2,986 women with a singleton pregnancy, consecutively enrolled before 17 weeks of gestation, who had routine prenatal follow-up at the CAOCR until delivery during the study period (2008-2012). The first ultrasound and Doppler evaluations for each patient obtained at 20-24 weeks of gestation were analyzed. Fetuses with congenital malformations or genetic abnormalities identified prenatally or at birth were excluded from the analysis.

\section{Ultrasound and Doppler Measurements}

Ultrasound and Doppler studies were performed using General Electric Voluson Expert and Voluson E8 (GE Healthcare, Milwaukee, WI, USA) ultrasound systems and 5- to 2-MHz probes. Gestational age was based on the last menstrual period and confirmed by crown-rump length measurement or by second-trimester ultrasound. EFW was calculated using the Hadlock formula [28] based on the combination of biparietal diameter, head circumference, abdominal circumference, and femur length. Normal EFW was considered to be $\geq 10$ th percentile and reduced EFW was considered to be $<10$ th percentile for gestational age [29].

Doppler evaluation of the UA was performed in a free loop of the umbilical cord, the MCA in a cross-sectional view of the fetal head in the vascular circle of Willis at approximately $1 \mathrm{~cm}$ after its origin from the internal carotid artery, and the uterine arteries (UtA) in a parasagittal view of the uterus $1 \mathrm{~cm}$ above the virtual crossing with the iliac artery [30]. The mean uterine artery pulsatility index (UtA-PI) was estimated as the average of the left and right UtAs. The size of the Doppler sample gate was adjusted to cover the entire interrogated vessel. Doppler recordings were obtained in the absence of maternal or fetal movements with an angle of insonation as close as possible to $0^{\circ}$. Using a high-pass wall filter of $60 \mathrm{MHz}$, each vessel was sampled two to three times and the mean pulsatility index was calculated. For the UtA and UA, a pulsatility index value $>95$ th percentile was considered abnormal [31]. The cerebroplacental ratio (CPR) was calculated as follows: middle cerebral artery pulsatility index (MCA-PI) / UA-PI; a CPR or MCA-PI $<5$ th percentile for gestational age was considered abnormal [31]. All women were scheduled to have an ultrasound examination every 4 weeks until 28 weeks of gestation and every 2 weeks thereafter until delivery.

\section{Clinical Outcomes}

In this study, we aimed to explore the association between abnormal Doppler parameters at 20-24 weeks of gestation and small fetal size later in pregnancy or at birth. We also determined whether this association is modified by abnormal fetal size $($ EFW $<10$ th percentile) at 20-24 weeks of gestation. All fetuses were followed until delivery and the clinical outcomes were defined as follows: (1) early SGA as an EFW $<10$ th percentile at $<34$ weeks of gestation [32], (2) late SGA as an EFW <10th percentile at $\geq 34$ weeks of gestation $[33,34]$, and (3) SGA at birth as birthweight $<10$ th percentile [35]. The information provided by Doppler parameters at 20-24 weeks of gestation was not used for clinical management. 
Table 1. Clinical characteristics and outcomes of the study groups

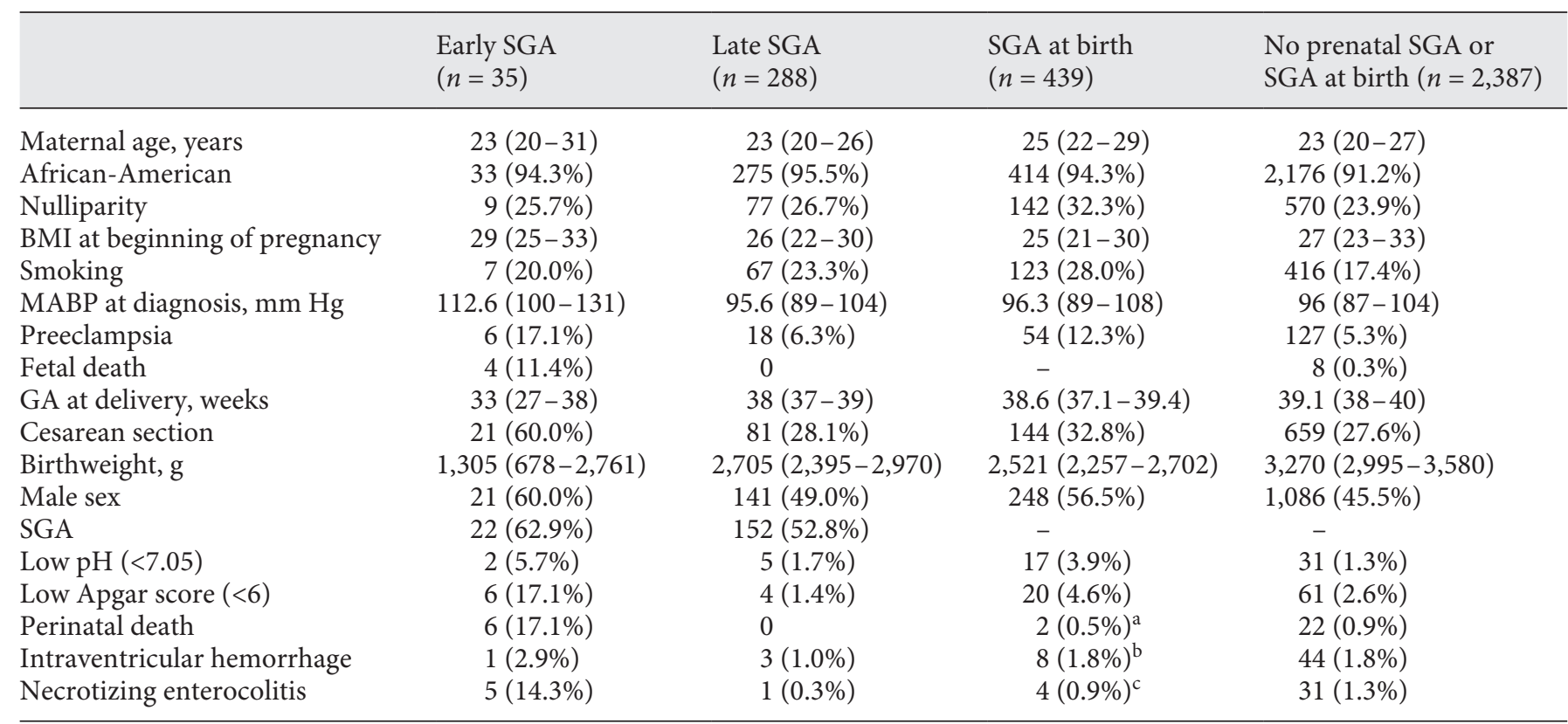

Values are presented as $n$ (\%) or median (interquartile range). BMI, body mass index; GA, gestational age; MABP, mean arterial blood pressure; SGA, small for gestational age. ${ }^{a}$ Neonatal. ${ }^{b}$ One with early SGA and two with late SGA. ${ }^{c}$ Three with early SGA.

\section{Statistical Analysis}

The diagnostic performance of all Doppler parameters for early and late SGA as well as for SGA at birth was estimated. Relative risk (RR) and odds ratios (OR) were calculated and the analysis accounted for potential confounders such as maternal age, gestational age at examination, mean arterial blood pressure, smoking, parity, alcohol and drug use, and body mass index. Differences in the CPR at 20-24 weeks in fetuses who were later diagnosed with early or late SGA were evaluated using the Wilcoxon rank sum test. A $p$ value $<0.05$ was considered statistically significant. Analyses were performed using SPSS ${ }^{\circledR}$ Version 19 (IBM Corp., Armonk, NY, USA) and MedCalc ${ }^{\circledR}$ 9.0.1.0 (MedCalc Software bvba, Ostend, Belgium) statistical software. RRs were obtained by a Poisson regression model with robust estimation of the variance using the "geepack" package under the R statistical environment (www. r-project.org). The primary measure used to rank the Doppler parameters based on their prediction performance was the positive likelihood ratio $(\mathrm{LR}+)$.

\section{Results}

This study included 2,986 patients; the success rate for obtaining Doppler parameters was as follows: UA-PI in 2,829 fetuses (94.7\%; variation among individual measurements: median 4.9\%, interquartile range [IQR] 2.7$10 \%$ ); MCA-PI and CPR in 2,505 fetuses (83.6\%; variation among individual measurements: median 3.8\%, IQR,
2.4-6.7\%); and mean UtA-PI in 2,848 women (95.3\%; variation among individual measurements: median $13 \%$, IQR 3.5-15.7\%). The prevalence of early SGA was $1.1 \%$ $(n=35 / 2,986)$, of late SGA $9.6 \%(n=288 / 2,986)$, and of SGA at birth $14.7 \%(n=439 / 2,986)$. The demographic characteristics of the study population according to outcome groups are described in Table 1.

The study cohort was stratified according to the EFW calculated during the first ultrasound examination at 20 24 weeks; 2,800 women (93.8\%) had fetuses with an EFW $\geq 10$ th percentile, and $186(6.2 \%)$ had fetuses with an EFW $<10$ th percentile. In fetuses with an EFW $\geq 10$ th percentile, $18(0.6 \%)$ had early SGA and $231(8.2 \%)$ had late SGA, while among those with an EFW $<10$ th percentile, $17(9.1 \%)$ had early SGA and 57 (30.6\%) had late SGA. The increase in the percentage of early and late SGA among fetuses with an EFW $<10$ th percentile compared to those with an EFW $\geq 10$ th percentile was significant ( $p<0.001$ for both) (Fig. 1). There were 13 fetal deaths (Table 2): 4 fetuses with an EFW $<10$ th percentile $(4 / 186$, $2.1 \%)$ and 9 fetuses with an EFW $\geq 10$ th percentile $(9 / 2,800,0.3 \%)$. The rate of SGA at birth in fetuses with an EFW <10th percentile was higher $(74 / 186,39.8 \%)$ than in those with an EFW $\geq 10$ th percentile $(365 / 2,800,13.1 \%)$ $(p<0.0001)$. Table 3 shows the clinical characteristics and 
Fig. 1. Outcomes for 2,986 fetuses evaluated at 20-24 weeks and classified according to estimated fetal weight (EFW) and further development of early or late small-forgestational-age (SGA) fetuses and SGA newborns. FGR, fetal growth restriction; IUFD, intrauterine fetal death.

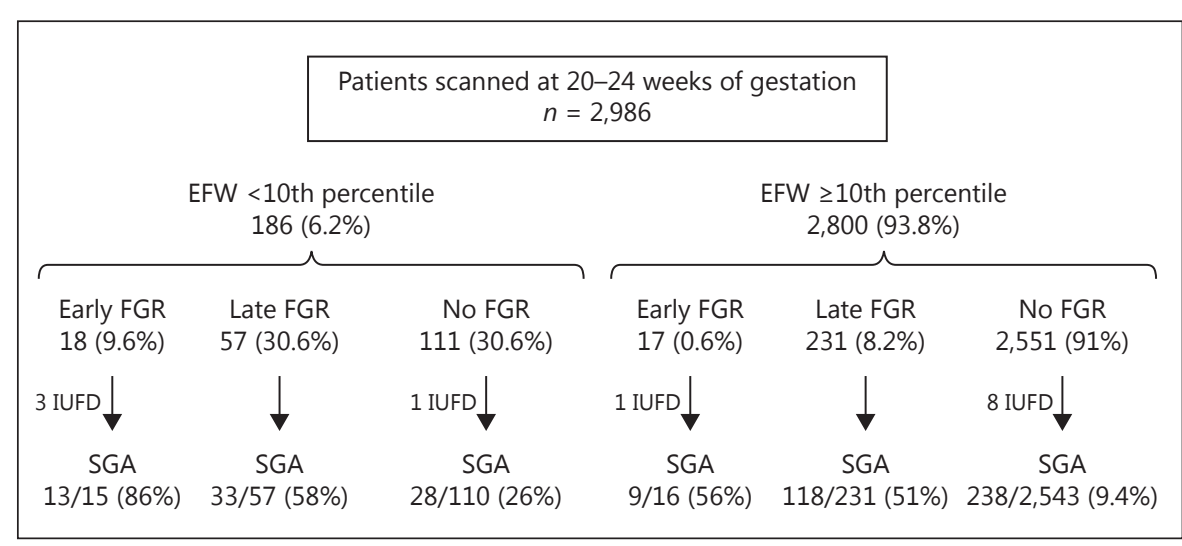

Table 2. Clinical characteristics of patients with fetal demise $(n=$ 13)

EFW $<10$ th percentile at $20-24$ weeks

Age, years

Body mass index

Mean arterial blood pressure, $\mathrm{mm} \mathrm{Hg}$

Smoking

Preeclampsia

Chronic hypertension

Gestational diabetes mellitus

Gestational age at delivery, weeks

Birthweight, $\mathrm{g}$

UA-PI $>95$ th percentile

Cerebroplacental ratio $<5$ th percentile Mean UtA-PI $>95$ th percentile

Values are presented as $n$ (\%) or median (interquartile range). EFW, estimated fetal weight; UA-PI, umbilical artery pulsatility index; UtA-PI, uterine artery pulsatility index.

perinatal outcomes of fetuses with an EFW $<10$ th or $\geq 10$ th percentile at $20-24$ weeks of gestation.

The median CPR at 20-24 weeks of gestation was significantly lower in fetuses who later developed early SGA as compared to those presenting late SGA, SGA at birth, or with normal fetal size and birthweight (all $p<0.05)$. No differences in the median CPR were observed among fetuses later presenting late SGA or SGA at birth or fetuses presenting with normal size during pregnancy and at birth (Fig. 2).

\section{Doppler Parameters at 20-24 Weeks of Gestation and in Early SGA Fetuses}

Among all Doppler parameters, the MCA-PI showed the lowest LR+ for the association between early or late SGA and SGA at birth. The diagnostic performance of

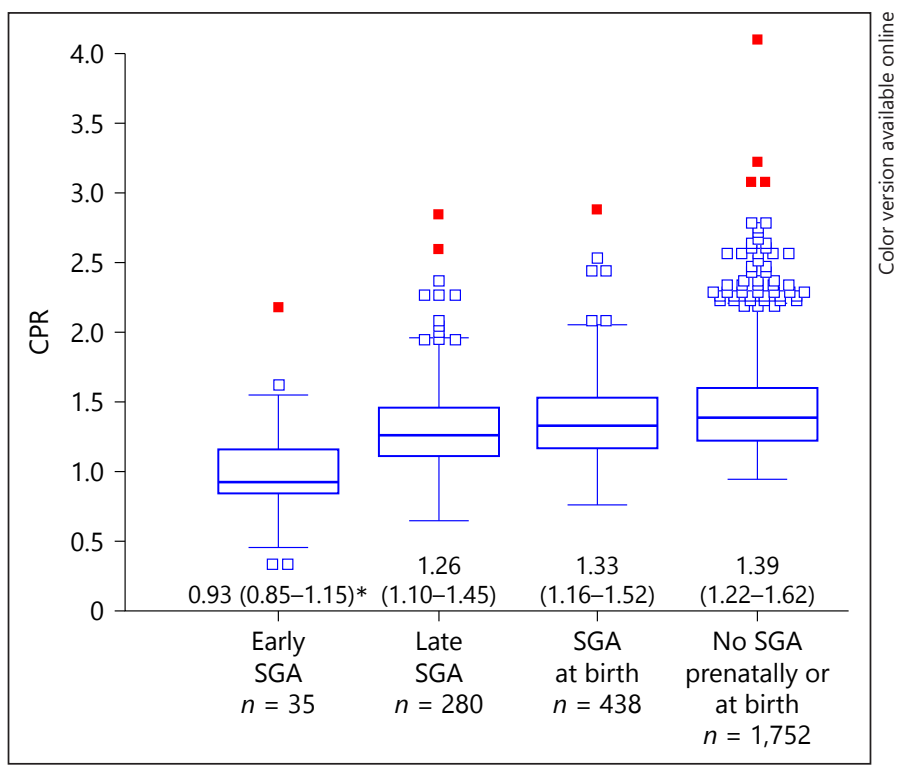

Fig. 2. Distribution of the cerebroplacental ratio (CPR) values at 20-24 weeks of gestation for fetuses who later in pregnancy showed early small for gestational age (SGA; estimated fetal weight $<10$ th percentile) $<34$ weeks of gestation, late SGA $\geq 34$ weeks of gestation, or SGA at birth (birthweight $<10$ th percentile) as well as for fetuses of normal size during pregnancy and at birth. ${ }^{*} p<0.05$ in comparison to any other group.

Doppler parameters for the subsequent development of early SGA was as follows (Table 4): For the complete study group: (1) CPR <5th percentile: sensitivity $54 \%$, false-positive rate (FPR) 7\%, positive predictive value (PPV) $9.1 \%$, negative predictive value (NPV) 99.4\%, LR+ 8.2 (95\% CI 5.7-12.0), and RR 15.4 (95\% CI 7.7-30.7); (2) UA-PI $>95$ th percentile: sensitivity $60.6 \%$, FPR $8 \%$, PPV 8.3\%, NPV 99.5\%, LR+ 7.6 (95\% CI 5.6-10.0), and RR 16.4 (95\% CI 8.2-32.5); and (3) UtA-PI >95th percentile: sensitivity 43.3\%, FPR 9\%, PPV 4.8\%, NPV 99.3\%, LR+ 4.7 (95\% CI 
Table 3. Clinical characteristics and outcomes of the study group according to estimated fetal weight at 20-24 weeks of gestation

\begin{tabular}{lccc}
\hline & $\begin{array}{l}\text { EFW }<10 \text { th percentile } \\
(n=186)\end{array}$ & $\begin{array}{l}\text { EFW } \geq 10 \text { percentile } \\
(n=2,800)\end{array}$ & $p$ value \\
\hline Low Apgar score & $7(3.7 \%)$ & $70(2.5 \%)$ & 0.41 \\
Perinatal death & $5(2.6 \%)^{\mathrm{a}}$ & $25(0.9 \%)$ & 0.03 \\
pH $<7.05$ & 0 & $44(1.5 \%)$ & 0.11 \\
Intraventricular hemorrhage & $5(2.6 \%)$ & $48(1.7 \%)$ & 0.37 \\
Necrotizing enterocolitis & $5(2.6 \%)^{\mathrm{a}}$ & $33(1.1 \%)$ & 0.08 \\
Preeclampsia & $13(6.9 \%)$ & $167(5.9 \%)$ & 0.9 \\
African-American & $163(87.6 \%)$ & $2,565(91.6 \%)$ & 0.9 \\
Female sex & $100(53.7 \%)$ & $1,299(46.4 \%)$ & 0.9 \\
Fetal death & $4(2.1 \%)^{\mathrm{a}}$ & $9(0.3 \%)$ & $<0.006$ \\
Birthweight, g & $2,532(1,398-3,080)^{\mathrm{a}}$ & $3,180(2,822-3,510)$ & 0.005 \\
Gestational age at delivery, weeks & $37(33-40)^{\mathrm{a}}$ & $39(37-40)$ & 1.0 \\
Cesarean section & $54(29.0 \%)$ & $782(27.9 \%)$ & \\
\hline
\end{tabular}

Values are presented as $n(\%)$ or median (interquartile range). EFW, estimated fetal weight. ${ }^{a} \mathrm{p}<0.05$.

Table 4. Associations of abnormal Doppler parameters at 20-24 weeks of gestation and early small for gestational age fetuses (estimated fetal weight $<10$ th percentile before 34 weeks of gestation)

\begin{tabular}{|c|c|c|c|c|c|c|c|c|c|}
\hline Doppler & $\begin{array}{l}\mathrm{SN} \\
\%\end{array}$ & $\begin{array}{l}\text { SP } \\
\%\end{array}$ & $\begin{array}{l}\text { PPV, } \\
\%\end{array}$ & $\begin{array}{l}\text { NPV, } \\
\%\end{array}$ & $\begin{array}{l}\mathrm{LR}+ \\
(95 \% \mathrm{CI})\end{array}$ & $\begin{array}{l}\text { LR- } \\
(95 \% \text { CI })\end{array}$ & $\begin{array}{l}\text { Unadjusted OR } \\
(95 \% \text { CI })\end{array}$ & $\begin{array}{l}\text { Adjusted OR } \\
(95 \% \text { CI })\end{array}$ & $\begin{array}{l}\text { RR } \\
(95 \% \mathrm{CI})\end{array}$ \\
\hline \multicolumn{10}{|c|}{ All study groups (prevalence $\mathrm{n}=35 ; 1.2 \%$ ) } \\
\hline UtA-PI & 43.3 & 91.0 & 4.8 & 99.3 & $4.7(3.1-7.2)$ & $0.6(0.5-0.8)$ & $7.6(3.6-15.7)$ & $6.5(3.6-10.7)$ & $7.3(3.6-14.8)$ \\
\hline CPR or UtA-PI & 74.1 & 83.9 & 5.3 & 99.6 & $4.6(3.6-5.8)$ & $0.3(0.2-0.6)$ & $15(6.7-33.8)$ & $11.7(5.1-27.0)$ & $14.2(6.4-31.7)$ \\
\hline UA-PI & 60.6 & 92.0 & 8.3 & 99.5 & $7.6(5.6-10.0)$ & $0.4(0.3-0.7)$ & $17.7(8.7-36.2)$ & $24.5(13.6-45.4)$ & $16.4(8.2-32.5)$ \\
\hline CPR & 69.2 & 93.2 & 47.4 & 97.2 & $10(5.1-21)$ & $0.3(0.2-0.8)$ & $31.1(8.1-118.7)$ & $41.6(8.2-327.7)$ & $16.8(5.7-49.3)$ \\
\hline UtA-PI & 28.6 & 88.4 & 17.4 & 93.5 & $2.5(0.9-6.3)$ & $0.8(0.6-1.1)$ & $3.1(0.9-10.1)$ & $2.3(0.4-10)$ & $2.7(0.9-7.90)$ \\
\hline CPR or UtA-PI & 84.6 & 81.7 & 28.9 & 98.4 & $4.6(3.0-7.0)$ & $0.2(0.1-0.7)$ & $24.6(5.1-117.6)$ & $20.3(3.9-104.6)$ & $17.8(4.1-76.8)$ \\
\hline UA-PI & 86.7 & 89.0 & 41.9 & 97.6 & $7.9(4.9-13)$ & $0.2(0.04-0.5)$ & $52.3(10.9-251)$ & $91.6(14.8-1,239.8)$ & $30.8(7.3-129.7)$ \\
\hline MCA-PI & 20.0 & 90.1 & 16.7 & 91.9 & $2.0(0.7-6.2)$ & $0.9(0.7-1.2)$ & $2.3(0.6-8.9)$ & $1.9(0.3-8.2)$ & $2.1(0.6-6.6)$ \\
\hline \multicolumn{10}{|c|}{$E F W \geq 10$ th percentile (prevalence $\mathrm{n}=18 ; 0.6 \%)$} \\
\hline MCA-PI & 33.3 & 88.2 & 2.1 & 99.4 & $2.8(1.5-5.5)$ & $0.8(0.6-1.1)$ & $3.7(1.4-10.1)$ & $3.3(1.5-6.7)$ & $3.7(1.4-9.7)$ \\
\hline
\end{tabular}

ORs adjusted for maternal age, race, nulliparity, smoking, alcohol use, drug use, pre-pregnancy body mass index, and mean arterial blood pressure. CI, confidence interval; CPR, cerebroplacental ratio $<5$ th percentile; EFW, estimated fetal weight; LR-, negative likelihood ratio; LR+, positive likelihood ratio; MCA-PI, middle cerebral artery pulsatility index <5th percentile; NPV, negative predictive value; OR, odds ratio; PPV, positive predictive value; RR, relative risk; SN, sensitivity; SP, specificity; UA-PI, umbilical artery pulsatility index $>95$ th percentile; UtA-PI, uterine artery pulsatility index $>95$ th percentile.

3.1-7.2), and RR 7.3 (95\% CI 3.6-14.8). For fetuses with an EFW <10th percentile: (1) CPR <5th percentile: sensitivity $69.2 \%$, FPR $6.8 \%$, PPV 47.4\%, NPV 97.2\%, LR+ 10.0 (95\% CI 5.1-21), and RR 16.8 (95\% CI 5.7-49.3); and (2) UA-PI >95th percentile: sensitivity $86.7 \%$, FPR $11 \%$, PPV
41.9\%, NPV 97.6\%, LR+ 7.9 (95\% CI 4.9-13.0), and RR 30.8 (95\% CI 7.3-129.7). The diagnostic performance of Doppler parameters for early SGA in fetuses with an EFW $\geq 10$ percentile at $20-24$ weeks of gestation was similar to that observed in the entire study population. 
Table 5. Diagnostic performance, likelihood ratios, and associations of Doppler parameters at $20-24$ weeks of gestation and late small for gestational age fetuses (estimated fetal weight $<10$ th percentile at $\geq 34$ weeks of gestation)

\begin{tabular}{|c|c|c|c|c|c|c|c|c|c|}
\hline Doppler & $\begin{array}{l}\mathrm{SN}, \\
\%\end{array}$ & $\begin{array}{l}\text { SP, } \\
\%\end{array}$ & $\begin{array}{l}\text { PPV, } \\
\%\end{array}$ & $\begin{array}{l}\text { NPV, } \\
\%\end{array}$ & $\begin{array}{l}\mathrm{LR}+ \\
(95 \% \mathrm{CI})\end{array}$ & $\begin{array}{l}\text { LR- } \\
(95 \% \mathrm{CI})\end{array}$ & $\begin{array}{l}\text { Unadjusted OR } \\
(95 \% \mathrm{CI})\end{array}$ & $\begin{array}{l}\text { Adjusted OR } \\
(95 \% \text { CI })\end{array}$ & $\begin{array}{l}\text { RR } \\
(95 \% \mathrm{CI})\end{array}$ \\
\hline \multicolumn{10}{|c|}{ All (prevalence $\mathrm{n}=288 ; 10.2 \%)$} \\
\hline $\mathrm{CPR}$ & 10.8 & 93.1 & 14.1 & 90.9 & $1.6(1.1-2.3)$ & $0.9(0.9-1.0)$ & $1.6(1.1-2.5)$ & $1.6(1-2.5)$ & $1.5(1.1-2.2)$ \\
\hline UtA-PI & 14.5 & 91.0 & 14.8 & 90.8 & $1.6(1.2-2.2)$ & $0.9(0.9-0.99)$ & $1.7(1.2-2.5)$ & $1.7(1.2-2.5)$ & $1.6(1.2-2.2)$ \\
\hline CPR or UtA-PI & 24.8 & 82.3 & 14.1 & 91.2 & $1.5(1.2-1.9)$ & $0.9(0.8-0.9)$ & $1.7(1.3-2.4)$ & $1.7(1.3-2.4)$ & $1.6(1.2-2.1)$ \\
\hline UA-PI & 9.9 & 91.6 & 11.2 & 90.5 & $1.2(0.8-1.7)$ & $0.9(0.9-1.1)$ & $1.2(0.8-1.8)$ & $1.2(0.8-1.8)$ & $1.2(0.8-1.7)$ \\
\hline MCA-PI & 14.1 & 88.4 & 11.3 & 90.7 & $1.2(0.9-1.7)$ & $0.9(0.9-1.0)$ & $1.2(0.9-1.8)$ & $1.2(0.8-1.8)$ & $1.2(0.9-1.7)$ \\
\hline \multicolumn{10}{|c|}{$E F W<10$ th percentile (prevalence $\mathrm{n}=57 ; 30.6 \%$ ) } \\
\hline $\mathrm{CPR}$ & 7.0 & 86.4 & 15.8 & 71.8 & $0.5(0.2-1.7)$ & $1.1(0.9-1.2)$ & $0.5(0.1-1.7)$ & $0.4(0.1-1.5)$ & $0.6(0.2-1.6)$ \\
\hline UtA-PI & 12.0 & 86.7 & 26.1 & 71.6 & $0.9(0.4-2.2)$ & $1.0(0.9-1.2)$ & $0.9(0.4-2.4)$ & $0.8(0.3-2.4)$ & $0.9(0.4-1.9)$ \\
\hline CPR or UtA-PI & 20.1 & 75.4 & 23.7 & 72.4 & $0.8(0.4-1.7)$ & $1.0(0.9-1.3)$ & $0.8(0.4-1.9)$ & $0.8(0.3-2.1)$ & $0.9(0.4-1.6)$ \\
\hline UA-PI & 6.0 & 78.1 & 9.7 & 68.0 & $0.3(0.1-1.4)$ & $1.2(0.1-1.4)$ & $0.2(0.1-0.8)$ & $0.2(0-0.6)$ & $0.3(0.1-0.9)$ \\
\hline MCA-PI & 11.6 & 89.4 & 27.8 & 74.3 & $1.1(0.4-2.9)$ & $1.0(0.8-1.1)$ & $1.1(0.4-3.2)$ & $1.1(0.3-3.2)$ & $1.0(0.5-2.4)$ \\
\hline \multicolumn{10}{|c|}{$E F W>10$ th percentile (prevalence $\mathrm{n}=231 ; 8.2 \%)$} \\
\hline CPR & 11.7 & 93.4 & 13.9 & 92.1 & $1.8(1.2-2.7)$ & $0.9(0.9-1.0)$ & $1.8(1.1-2.9)$ & $1.9(1.1-2.5)$ & $1.8(1.1-2.6)$ \\
\hline UtA-PI & 15.0 & 91.2 & 13.7 & 92.1 & $1.7(1.2-2.4)$ & $0.9(0.9-1.0)$ & $1.8(1.2-2.7)$ & $1.9(1.2-2.8)$ & $1.7(1.2-2.4)$ \\
\hline CPR or UtA-PI & 25.6 & 84.5 & 13.4 & 92.3 & $1.6(1.3-2.1)$ & $0.9(0.8-1.0)$ & $1.9(1.4-2.6)$ & $1.9(1.4-2.7)$ & $1.7(1.3-2.3)$ \\
\hline UA-PI & 10.8 & 92.3 & 11.4 & 91.8 & $1.4(0.9-2.1)$ & $1.0(0.9-1.0)$ & $1.4(0.9-2.3)$ & $1.4(1-2.3)$ & $1.4(0.9-2.0)$ \\
\hline MCA-PI & 14.6 & 88.3 & 10.3 & 91.8 & $1.2(0.9-1.8)$ & $1.0(0.9-1.0)$ & $1.3(0.9-1.9)$ & $1.3(0.8-1.9)$ & $1.3(0.8-1.8)$ \\
\hline
\end{tabular}

ORs adjusted for maternal age, race, nulliparity, smoking, alcohol use, drug use, pre-pregnancy body mass index, and mean arterial blood pressure. CI, confidence interval; CPR, cerebroplacental ratio $<5$ th percentile; EFW, estimated fetal weight; LR-, negative likelihood ratio; LR+, positive likelihood ratio; MCA-PI, middle cerebral artery pulsatility index $<$ th percentile; NPV, negative predictive value; OR, odds ratio; PPV, positive predictive value; RR, relative risk; SN, sensitivity; SP, specificity; UA-PI, umbilical artery pulsatility index $>95$ th percentile; UtA-PI, uterine artery pulsatility index $>95$ th percentile.

Table 6. Diagnostic performance, likelihood ratios, and associations of Doppler parameters at 20-24 weeks of gestation and small for gestational age at birth (birthweight $<10$ th percentile)

\begin{tabular}{|c|c|c|c|c|c|c|c|c|c|}
\hline Doppler & $\begin{array}{l}\text { SN, } \\
\%\end{array}$ & $\begin{array}{l}\mathrm{SP} \\
\%\end{array}$ & $\begin{array}{l}\text { PPV, } \\
\%\end{array}$ & $\begin{array}{l}\text { NPV, } \\
\%\end{array}$ & $\begin{array}{l}\text { LR+ } \\
(95 \% \text { CI })\end{array}$ & $\begin{array}{l}\text { LR- } \\
(95 \% \text { CI })\end{array}$ & $\begin{array}{l}\text { Unadjusted OR } \\
(95 \% \text { CI })\end{array}$ & $\begin{array}{l}\text { Adjusted OR } \\
(95 \% \text { CI })\end{array}$ & $\begin{array}{l}\text { RR } \\
(95 \% \text { CI })\end{array}$ \\
\hline \multicolumn{10}{|c|}{ All (prevalence $\mathrm{n}=439 ; 15.6 \%$ ) } \\
\hline $\mathrm{CPR}$ & 12.1 & 93.5 & 23.8 & 86.3 & $1.9(1.4-2.6)$ & $0.9(0.9-1.0)$ & $2.0(1.4-2.8)$ & $1.8(1.2-2.6)$ & $1.7(1.3-2.3)$ \\
\hline UtA-PI & 21.0 & 92.5 & 32.5 & 87.2 & $2.8(2.2-3.5)$ & $0.9(0.8-0.9)$ & $3.3(2.4-4.3)$ & $3.3(2.4-4.4)$ & $2.5(2.1-3.1)$ \\
\hline CPR or UtA-PI & 30.9 & 85.7 & 27.3 & 87.7 & $2.2(1.8-2.6)$ & $0.8(0.7-0.9)$ & $2.7(2.1-3.5)$ & $2.6(2.0-3.2)$ & $2.2(1.8-2.7)$ \\
\hline UA-PI & 13.3 & 92.2 & 22.8 & 86.0 & $1.7(1.3-2.3)$ & $0.9(0.9-0.98)$ & $1.8(1.3-2.5)$ & $1.8(1.3-2.5)$ & $1.6(1.3-2.1)$ \\
\hline MCA-PI & 11.7 & 88.1 & 14.2 & 85.5 & $1.0(0.7-1.3)$ & $1.0(0.96-1.04)$ & $0.9(0.7-1.4)$ & $0.9(0.6-1.2)$ & $0.9(0.7-1.3)$ \\
\hline \multicolumn{10}{|c|}{$E F W<10$ th percentile (prevalence $\mathrm{n}=74 ; 39.8 \%$ ) } \\
\hline $\mathrm{CPR}$ & 20.6 & 93.9 & 68.4 & 64.7 & $3.4(1.4-8.4)$ & $0.8(0.7-1.0)$ & $4.0(1.4-11.1)$ & $3.0(1-10.1)$ & $1.9(1.0-3.5)$ \\
\hline UtA-PI & 22.5 & 93.5 & 69.6 & 64.5 & $3.4(1.5-7.9)$ & $0.8(0.7-1.0)$ & $4.2(1.6-10.7)$ & $4.0(1.4-12.9)$ & $2.0(1.4-2.7)$ \\
\hline CPR or UtA-PI & 41.2 & 87.7 & 68.4 & 69.9 & $3.3(1.8-6.2)$ & $0.7(0.5-0.8)$ & $5.0(2.3-11.0)$ & $4.5(1.9-10.6)$ & $2.2(1.6-3.2)$ \\
\hline UA-PI & 22.5 & 86.0 & 51.6 & 62.6 & $1.6(0.8-3.0)$ & $0.9(0.8-1.0)$ & $1.8(0.8-3.9)$ & $1.4(0.6-3.4)$ & $1.4(0.9-2.1)$ \\
\hline MCA-PI & 15.6 & 92.2 & 55.6 & 63.5 & $2.0(0.8-4.8)$ & $0.9(0.8-1.0)$ & $2.2(0.8-5.8)$ & $2.2(0.7-7)$ & $1.5(0.9-2.4)$ \\
\hline \multicolumn{10}{|c|}{$E F W>10$ th percentile (prevalence $\mathrm{n}=365 ; 13.1 \%)$} \\
\hline $\mathrm{CPR}$ & 10.3 & 93.5 & 18.7 & 87.8 & $1.6(1.1-2.3)$ & $1.0(0.9-1.0)$ & $1.6(1.1-2.5)$ & $1.5(1-2.3)$ & $1.5(1.1-2.1)$ \\
\hline UtA-PI & 20.7 & 92.4 & 29.0 & 88.6 & $2.7(2.1-3.5)$ & $0.9(0.8-0.9)$ & $3.2(2.3-4.3)$ & $3.2(2.3-4.4)$ & $2.6(2.0-3.2)$ \\
\hline CPR or UtA-PI & 29.0 & 85.1 & 23.3 & 88.8 & $2.0(1.6-2.5)$ & $0.8(0.8-0.9)$ & $2.4(1.8-3.2)$ & $2.3(1.7-3.1)$ & $2.0(1.7-2.6)$ \\
\hline UA-PI & 11.4 & 92.5 & 18.6 & 87.5 & $1.5(1.1-2.1)$ & $1.0(0.9-1.0)$ & $1.6(1.1-2.3)$ & $1.6(1.1-2.4)$ & $1.5(1.1-2.0)$ \\
\hline MCA-PI & 10.9 & 87.9 & 11.7 & 87.1 & $1.0(0.7-1.3)$ & $1.0(1.0-1.0)$ & $0.9(0.6-1.3)$ & $0.8(0.5-1.2)$ & $0.9(0.6-1.2)$ \\
\hline
\end{tabular}

ORs adjusted for maternal age, race, nulliparity, smoking, alcohol use, drug use, pre-pregnancy body mass index, and mean arterial blood pressure. CI, confidence interval; CPR, cerebroplacental ratio <5th percentile; EFW, estimated fetal weight; LR-, negative likelihood ratio; LR+, positive likelihood ratio; MCA-PI, middle cerebral artery pulsatility index $<$ th percentile; NPV, negative predictive value; OR, odds ratio; PPV, positive predictive value; RR, relative risk; SN, sensitivity; SP, specificity; UA-PI, umbilical artery pulsatility index $>95$ th percentile; UtA-PI, uterine artery pulsatility index $>95$ th percentile.

CPR $<5$ th Percentile at 20-24 Weeks of Gestation and Fetal Size Later in Pregnancy
Fetal Diagn Ther 2018;44:112-123 DOI: $10.1159 / 000479684$ 
Doppler Parameters at 20-24 Weeks of Gestation and in Late SGA Fetuses

The diagnostic performance of Doppler parameters for the subsequent development of late SGA was as follows (Table 5): For the complete study group: (1) CPR $<5$ th percentile: sensitivity $10.8 \%$, FPR $6.9 \%$, PPV 14.1\%, NPV 90.9\%, LR+ 1.6 (95\% CI 1.1-2.3), and RR 1.5 (95\% CI 1.2-2.2); (2) UtA-PI >95th percentile: sensitivity $14.5 \%$, FPR 9\%, PPV 14.8\%, NPV 90.8\%, LR+ 1.6 (95\% CI 1.1-2.2), and RR 1.6 (95\% CI 1.2-2.2); and (3) UA-PI >95th percentile: sensitivity 9.9\%, FPR 8.4\%, PPV 11.2\%, NPV 90.5\%, LR+ 1.2 (95\% CI 0.8-1.7), and RR 1.2 (95\% CI 0.8-1.7). For fetuses with an EFW $<10$ th percentile: (1) CPR <5th percentile: sensitivity $7.0 \%$, FPR 13.6\%, PPV 15.8\%, NPV 71.8\%, LR+ 0.5 (95\% CI $0.2-1.7$ ), and RR 0.6 (95\% CI 0.2-1.6); and (2) UtA-PI $>95$ th percentile: sensitivity $12.0 \%$, FPR $13.3 \%$, PPV 26.1\%, NPV 71.6\%, LR+ 0.9 (95\% CI 0.4-2.2), and RR 0.9 (95\% CI 0.4-1.9). The diagnostic performance of Doppler parameters for late SGA in fetuses with an EFW $\geq 10$ percentile at $20-24$ weeks of gestation did not significantly vary from that observed for the entire study population.

Doppler Parameters at 20-24 Weeks of Gestation and in SGA at Birth

The diagnostic performance of Doppler parameters for SGA at birth was as follows (Table 6): For the complete study group: (1) CPR <5th percentile: sensitivity $12.1 \%$, FPR 6.5\%, PPV 23.8\%, NPV 86.3\%, LR+ 1.9 (95\% CI 1.42.6), and RR 1.7 (95\% CI 1.3-2.3); (2) UtA-PI >95th percentile: sensitivity $21.0 \%$, FPR 7.5\%, PPV 32.5\%, NPV 87.2\%, LR+ 2.8 (95\% CI 2.2-3.5), and RR 2.5 (95\% CI 2.1-3.1); and (3) UA-PI >95th percentile: sensitivity $13.3 \%$, FPR 7.8\%, PPV 22.8\%, NPV 86\%, LR+ 1.7 (95\% CI 1.3-2.3), and RR 1.6 (95\% CI 1.3-3.5). For fetuses with an EFW $<10$ th percentile: (1) CPR $<5$ th percentile: sensitivity $20.6 \%$, FPR 6.1\%, PPV 68.4\%, NPV 64.7\%, LR+ 3.4 (95\% CI 1.4-8.4), and RR 1.9 (95\% CI 1.3-2.8); and (2) UtA-PI >95th percentile: sensitivity $22.5 \%$, FPR 6.5\%, PPV 69.6\%, NPV 64.5\%, LR+ 3.4 (95\% CI 1.5-7.9), and RR 2.0 (95\% CI 1.4-2.7). The diagnostic performance of Doppler parameters for SGA at birth in fetuses with an EFW $\geq 10$ percentile at 20-24 weeks of gestation did not significantly vary from that observed for the entire study population.

Figure 3 shows the RRs (95\% CI) of early SGA (upper panel) and late SGA (lower panel) for fetuses at 20-24 weeks of gestation with a CPR $<5$ th percentile and an EFW less than a given cutoff. At any EFW percentile cut-

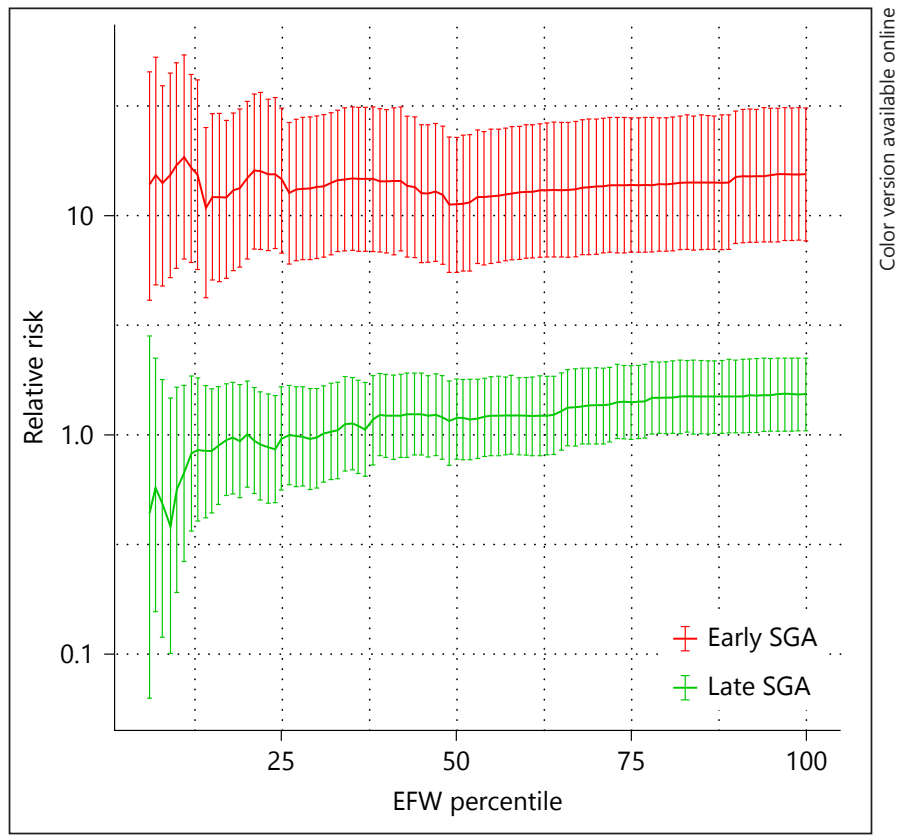

Fig. 3. Relative risks with $95 \%$ confidence intervals ( $y$ axis) for early small for gestational age (SGA) ( $<34$ weeks of gestation; upper panel) or late SGA ( $\geq 34$ weeks of gestation; lower panel) for fetuses with a cerebroplacental ratio $<5$ th percentile at 20-24 weeks of gestation and an estimated fetal weight (EFW) less than a given cutoff ( $x$ axis).

off, a reduced CPR significantly increased the risk of early SGA. The EFW cutoff at which the area under the receiver operating characteristics curve was highest (Fig. 4) was EFW 7th percentile and corresponded to a sensitivity of $73 \%$, a specificity of $94 \%$, and a LR+ of 12.16 for identification of early SGA.

\section{Predictive Performance of a $C P R<5$ th Percentile or a} UtA-PI $>95$ th Percentile

The sensitivity of this combined Doppler evaluation for the detection of early fetal growth restriction increased to $74.1 \%$ (from $54 \%$ ) and for late fetal growth restriction to $24.8 \%$ (from $10.8 \%$ ) compared to a CPR $<5$ th percentile alone, whereas the specificity was lower (83.9 and $84.10 \%$, respectively, compared to $93 \%$ for both with a $\mathrm{CPR}<5$ th percentile alone), thus resulting in lower positive LRs. Similar findings were observed for SGA at birth, where sensitivity increased from 21.0 to $30.9 \%$, but with lower specificity ( 85.7 vs. $92.5 \%$, respectively) when compared to a UtA-PI $>95$ th percentile alone, resulting in similar positive LRs. 


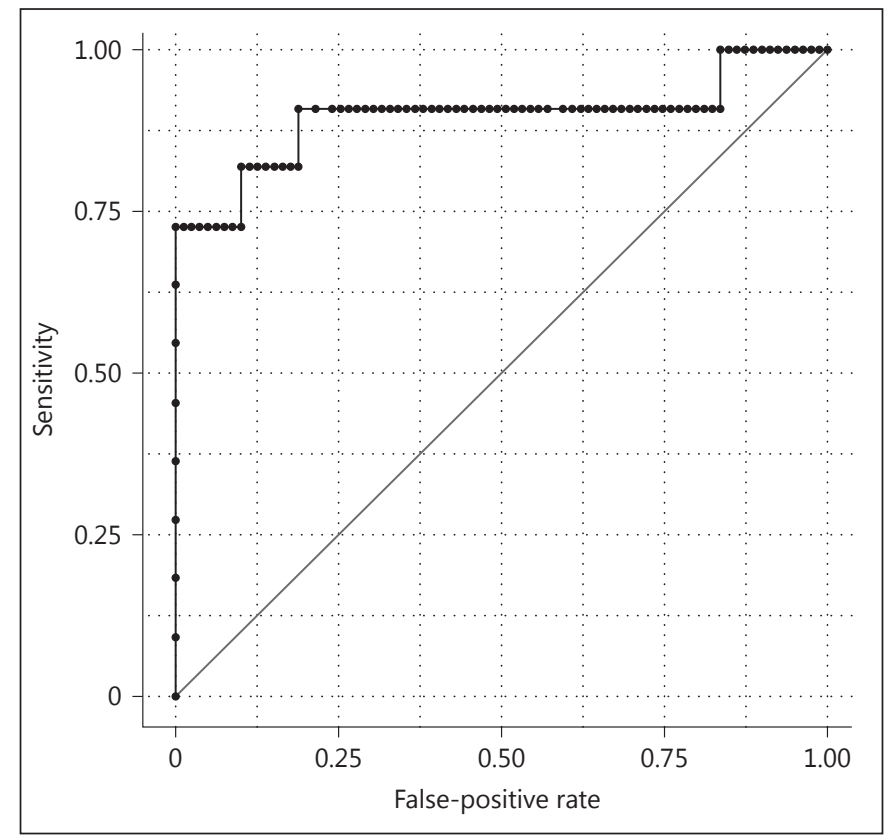

Fig. 4. The receiver operating characteristics curve shows early fetal growth restriction for fetuses with an abnormal cerebroplacental ratio $(<5$ th percentile) and an estimated fetal weight $<7$ th percentile.

\section{Discussion}

The principal findings of this study are as follows: (1) a CPR $<5$ th percentile at 20-24 weeks of gestation can detect fetuses who will show early SGA, late SGA, and SGA at birth; (2) a UtA-PI and an UA-PI > 95th percentile were also associated with the subsequent development of early SGA, late SGA, and SGA at birth; (3) a CPR $<5$ th percentile at 20-24 weeks of gestation had a LR+ of 10 for the detection of early SGA; (4) at an EFW corresponding to the 7th percentile at 20-24 weeks of gestation, a CPR $<5$ th percentile had an OR of 39.47 and a LR+ of 12.16 for the identification of early SGA. These results suggest that the ratio of the hemodynamic changes in the fetal-placental circulation and in the fetal brain at 20-24 weeks of gestation can be a sensitive tool for the early identification of women at risk of the subsequent development of early SGA.

\section{Early Evaluation of Doppler Parameters in the}

Assessment of Fetal Growth

Fetal Doppler velocimetry is usually performed after 24 weeks of gestation as a complementary method to the nonstress test and the fetal biophysical profile for the clinical management of SGA fetuses [26], while the UtAs are the vascular parameters most frequently evaluated at $<24$ weeks of gestation to identify fetuses at risk of reduced fetal growth later in pregnancy [36]. In accordance with previous studies [37-40], we found that an increased mean UtA-PI at $<24$ weeks of gestation was mainly associated with late SGA and with SGA at birth. Recent findings suggest that an interrogation of fetal vessels at 20-24 weeks of gestation may also play a role in the identification of the subsequent development of SGA. De Paco et al. [27] conducted a large study addressing the performance of the UA during the second-trimester ultrasound scan. The authors measured the UA-PI in 4,565 fetuses at 19-22 weeks of gestation and reported that an UA-PI $>90$ th percentile was significantly associated with the delivery of an SGA neonate (birthweight $<5$ th and $<10$ th percentiles) with a LR of 1.7 (95\% CI 1.2-2.4) for birthweight $<10$ th percentile. In the current study, we demonstrated a similar performance of the UA-PI $>90$ th percentile for the identification of women who subsequently delivered an SGA neonate (LR+ 1.7 [95\% CI 1.3-2.3]). A novel finding of our study indicates that an evaluation of the CPR at 20-24 weeks of gestation can detect fetuses who will show reduced size later in pregnancy. Indeed, a $\mathrm{CPR}<5$ th percentile in fetuses with an EFW $<10$ th percentile is also associated with a significantly higher risk of early SGA (LR+ 10.0 [95\% CI 5.1-21.0]). This early SGA group should be considered a high-risk group; according to our data, these patients had an $11.4 \%$ prevalence of fetal mortality. These pregnancies might benefit from close clinical surveillance to identify or prevent contributing factors that can increase the risk of perinatal mortality and morbidity [41-46].

\section{Doppler Velocimetry and Low EFW}

The study of the fetal circulation using Doppler ultrasound is mainly confined to the assessment of fetuses with reduced size/growth. The rationale for this approach is that Doppler velocimetry can characterize the fetal hemodynamic deterioration and contribute to the clinical management of these fetuses [47-49]. The UA remains the main Doppler parameter for fetal assessment; recent studies have shown that the measurement of the CPR improved the early identification of fetuses at a higher risk of adverse outcome [50-52]. Based on these findings, Figueras and Gratacos [53] proposed an alternative definition for late SGA that includes an EFW $<10$ th percentile, a decreased CPR, or an increased mean UtA-PI. These authors reported that the combination of an EFW $<10$ th percentile and abnormal Doppler parameters can identify more fetuses at risk of perinatal complications 
such as intrapartum fetal distress and neonatal acidosis. In the sequence of fetal Doppler deterioration, reduced diastolic velocity in the UA can be considered a manifestation of late hemodynamic deterioration. While the CPR represents a balance between the placental resistance to flow and the brain's compensatory mechanism associated with fetal growth restriction, it has been proposed that this parameter may be more sensitive to subtle fetal hemodynamic changes and that an abnormal CPR value may identify a fetus at risk of abnormal growth and perinatal complications earlier in gestation compared to a Doppler of the UA [52]. Indeed, we supported this hypothesis, presenting a novel finding that a reduced CPR at 20-24 weeks of gestation is significantly associated with an increased risk of early SGA.

\section{The CPR as a Manifestation of Reduced Fetal Size}

The importance of the CPR as a hemodynamic manifestation of blood flow redistribution in fetuses who are at the early stages of reduced fetal size was reported by Morales-Rosello et al. [54]. The authors demonstrated in fetuses with normal EFW that the closer the EFW is to the 10 th percentile, the lower the CPR. They evaluated 11,576 pregnant women and reported that the CPR 5th percentile corresponded to 0.6765 multiples of the median (MoM), and their results indicated that $6.0 \%$ of fetuses with an EFW between the 75th and 90th percentiles, 7.9\% of fetuses with an EFW between the 25th and 50th percentiles, and $11.6 \%$ of fetuses with an EFW between the 10th and 25th percentiles all had a CPR $\leq 0.6765 \mathrm{MoM}$. The authors also showed that fetuses with an EFW $<10$ th percentile had a $22.2 \%$ prevalence of a $\mathrm{CPR}<5$ th percentile suggesting that, although the fetuses had not reached the threshold of SGA, a low CPR $(<0.676 \mathrm{MoM})$ might be used as a surrogate of reduced size and as a potential predictor of neonatal neurodevelopmental impairment. This observation was supported by Prior et al. [55] who conducted a prospective observational study of 775 women with a low-risk term pregnancy who had a Doppler examination within $72 \mathrm{~h}$ of delivery. When the fetuses were divided into two groups according to the CPR measurement, using the cutoff value suggested by Morales-Rosello et al. [54] $(<0.6765 \mathrm{MoM}$ or $\geq 0.6765 \mathrm{MoM})$, the women with a CPR below the cutoff had a significantly increased risk of cesarean delivery due to fetal distress. Khalil et al. [56] reported that a low CPR, independent of the EFW, was associated with an increased prevalence of stillbirth and perinatal mortality [57]. Similar results were reported by Triunfo et al. [58] who showed that a low CPR in the third trimester of pregnancy had a higher association with adverse perinatal outcomes such as nonreassuring fetal status requiring emergency cesarean delivery, a 5 -min Apgar score $<7$, or neonatal metabolic acidosis at birth (UA pH $\leq 7.15$ and base excess $>12 \mathrm{mEq} / \mathrm{L}$ ) compared to EFW. These observations led to the evaluation of the CPR as a screening tool for pregnant women during the third trimester of pregnancy to identify fetuses at risk of late SGA $[59,60]$, stillbirth, low $\mathrm{pH}$ in the umbilical cord, low Apgar scores, cesarean delivery for fetal distress, and admission to the neonatal intensive care unit [60-62].

Additionally, an abnormal CPR for SGA fetuses is associated with a short interval to delivery [63], increased prevalence of abnormal fetal heart rate monitoring during labor [64], composite adverse perinatal outcome [65], and placental lesions associated with maternal underperfusion (e.g., muscularized arteries, atherosis, and mural hypertrophy) [66]. The Prospective Observational Trial to Optimize Pediatric Health in Intrauterine Growth Restriction (PORTO) study explored the utilization of the CPR for 881 growth-restricted fetuses at 33 weeks of gestation and reported that a CPR $<1$ was associated with an increased rate of perinatal complications $(18 \%)$ versus only $2 \%$ for fetuses with a CPR >1 (OR 11.7 [95\% CI 6.022.9]) [67]. The same group reported that, in a considerable proportion of cases, the CPR can improve in subsequent examinations, thus reducing the perinatal risks. From a total of 87 fetuses with a CPR $<1,45$ (52\%) remained abnormal in subsequent ultrasound scans, and 10 (22\%) had an adverse perinatal outcome, whereas of the $42(48 \%)$ fetuses who had an improved CPR, only 2 (5\%) had an abnormal perinatal outcome [68]. Collectively, this evidence suggests that the CPR might be an important tool in the estimation of perinatal risks for normal and complicated pregnancies.

Our study is the first to test the utilization of the CPR at 20-24 weeks of gestation in the risk assessment of subsequent fetal growth restriction. We identified already at the early stages of pregnancy (especially in fetuses with reduced size) patients who will subsequently have early SGA ( $<34$ weeks of gestation), late SGA, and SGA at birth. These findings are novel and suggest that hemodynamic changes in fetuses with affected growth can be identified in the second trimester of pregnancy.

\section{Clinical Implications}

Maternal-fetal Doppler evaluation conducted at 20-24 weeks of gestation is not universally accepted; however, available reports show that a mean UtA-PI $>95$ th percentile at this gestational age can identify women at risk of 
preeclampsia and SGA $[39,69]$. The evaluation of two additional fetal Doppler parameters - the UA and the MCA - in combination with EFW can improve the identification of fetuses at a higher risk of reduced size later in pregnancy. The presence of abnormal Doppler parameters at this gestational age might increase the frequency of clinical visits, but no decisions concerning delivery will be made. Fetuses with a reduced CPR might benefit from closer clinical surveillance, thus allowing the identification of the early stages of fetal decompensation for the purpose of steroid administration and the decision on the optimal time for delivery. Fetal and maternal Doppler parameters have the potential to improve the clinical information provided by the fetal biometric evaluation [70].

The strengths of our study are that (1) all fetuses were evaluated using the same protocol for biometric and Doppler measurements, and (2) clinical management and deliveries were performed at the CAOCR and followed the same standard guidelines. The information derived from the Doppler parameters at 20-24 weeks of gestation was not used for clinical management. Our study included a majority of African-American women, most of them parous, with a prevalence of $5-7 \%$ for preeclampsia. The diagnostic performance of Doppler parameters at 20-24 weeks of gestation to predict fetal growth restriction and SGA at birth might differ in other populations. Technical aspects and time constraints were the main reasons why not all Doppler measurement parameters were obtained from all patients; however, all women had at least two Doppler parameters evaluated. A limitation of this study is that the sample size did not provide sufficient power to detect differences in the prediction performance of different Doppler parameters. For example, the detec- tion of early SGA fetuses among those with an EFW $<10$ th percentile, demonstrating a significant improvement in sensitivity from 0.29 for UtA-PI to 0.69 for CPR (at the same FPR of about 10\%), would have required 28 cases to provide a power of $80 \%$, while only 18 cases were available in this study's cohort. As in all observational studies, causation cannot be determined apart from association.

\section{Conclusion}

At 20-24 weeks of gestation, an abnormal CPR $(<5$ th percentile) identifies one-half of the fetuses destined to be diagnosed as SGA $<34$ weeks at 7\% FPR (a 15.4-fold increase in the RR).

\section{Acknowledgments}

This research was supported, in part, by the Perinatology Research Branch, Division of Obstetrics and Maternal-Fetal Medicine, Division of Intramural Research, Eunice Kennedy Shriver National Institute of Child Health and Human Development, National Institutes of Health, U.S. Department of Health and Human Services (NICHD/NIH/DHHS) and, in part, with Federal funds from NICHD/NIH/DHHS under Contract No. HHSN275201300006C. The ultrasound experience and technical support of senior registered diagnostic medical sonographers Catherine Ducharme and Denise Haggerty are gratefully acknowledged.

\section{Disclosure Statement}

The authors report no conflicts of interest.

\section{References}

1 Lumey LH: Decreased birthweights in infants after maternal in utero exposure to the Dutch famine of 1944-1945. Paediatr Perinat Epidemiol 1992;6:240-253.

2 Stein AD, Ravelli AC, Lumey LH: Famine, third-trimester pregnancy weight gain, and intrauterine growth: the Dutch Famine Birth Cohort Study. Hum Biol 1995;67:135-150.

3 Lang U, Baker RS, Khoury J, Clark KE: Effects of chronic reduction in uterine blood flow on fetal and placental growth in the sheep. Am J Physiol Regul Integr Comp Physiol 2000; 279:R53-R59.

4 Williams SJ, Hemmings DG, Mitchell JM, McMillen IC, Davidge ST: Effects of maternal hypoxia or nutrient restriction during pregnancy on endothelial function in adult male rat offspring. J Physiol 2005;565:125-135.

5 Peeters LL, Sheldon RE, Jones MD Jr, Makowski EL, Meschia G: Blood flow to fetal organs as a function of arterial oxygen content. Am J Obstet Gynecol 1979;135:637-646.

6 Reuss ML, Rudolph AM: Distribution and recirculation of umbilical and systemic venous blood flow in fetal lambs during hypoxia. J Dev Physiol 1980;2:71-84.

7 Sidi D, Kuipers JR, Teitel D, Heymann MA, Rudolph AM: Developmental changes in oxygenation and circulatory responses to hypoxemia in lambs. Am J Physiol 1983;245:H674-H682.
8 Wladimiroff JW, vd Wijngaard JA, Degani S, Noordam MJ, van Eyck J, Tonge HM: Cerebral and umbilical arterial blood flow velocity waveforms in normal and growth-retarded pregnancies. Obstet Gynecol 1987;69:705709.

9 Di Renzo GC, Luzi G, Cucchia GC, Caserta G, Fusaro P, Perdikaris A, Cosmi EV: The role of Doppler technology in the evaluation of fetal hypoxia. Early Hum Dev 1992;29:259-267.

10 Lang U, Baker RS, Khoury J, Clark KE: Fetal umbilical vascular response to chronic reductions in uteroplacental blood flow in late-term sheep. Am J Obstet Gynecol 2002;187:178186 
11 Link G, Clark KE, Lang U: Umbilical blood flow during pregnancy: evidence for decreasing placental perfusion. Am J Obstet Gynecol 2007;196:489.e1-e7.

12 Cheema R, Dubiel M, Gudmundsson S: Fetal brain sparing is strongly related to the degree of increased placental vascular impedance. J Perinat Med 2006;34:318-322.

13 Akalin-Sel T, Nicolaides KH, Peacock J, Campbell S: Doppler dynamics and their complex interrelation with fetal oxygen pressure, carbon dioxide pressure, and $\mathrm{pH}$ in growth-retarded fetuses. Obstet Gynecol 1994;84:439-444.

14 Cruz-Martinez R, Figueras F, Hernandez-Andrade E, Oros D, Gratacos E: Fetal brain Doppler to predict cesarean delivery for nonreassuring fetal status in term small-for-gestational-age fetuses. Obstet Gynecol 2011;117: 618-626.

15 Eixarch E, Meler E, Iraola A, Illa M, Crispi F, Hernandez-Andrade E, Gratacos E, Figueras F: Neurodevelopmental outcome in 2-yearold infants who were small-for-gestational age term fetuses with cerebral blood flow redistribution. Ultrasound Obstet Gynecol 2008;32:894-899.

16 Cruz-Martinez R, Figueras F, BenavidesSerralde A, Crispi F, Hernandez-Andrade E, Gratacos E: Sequence of changes in myocardial performance index in relation to aortic isthmus and ductus venosus Doppler in fetuses with early-onset intrauterine growth restriction. Ultrasound Obstet Gynecol 2011; 38:179-184.

17 Oros D, Figueras F, Cruz-Martinez R, Meler E, Munmany M, Gratacos E: Longitudinal changes in uterine, umbilical and fetal cerebral Doppler indices in late-onset small-forgestational age fetuses. Ultrasound Obstet Gynecol 2011;37:191-195.

18 Cruz-Lemini M, Crispi F, Van Mieghem T, Pedraza D, Cruz-Martinez R, Acosta-Rojas R, Figueras F, Parra-Cordero M, Deprest J, Gratacos E: Risk of perinatal death in earlyonset intrauterine growth restriction according to gestational age and cardiovascular Doppler indices: a multicenter study. Fetal Diagn Ther 2012;32:116-122.

19 Demicheva E, Crispi F: Long-term follow-up of intrauterine growth restriction: cardiovascular disorders. Fetal Diagn Ther 2014;36: 143-153.

20 Karsdorp VH, van Vugt JM, van Geijn HP, Kostense PJ, Arduini D, Montenegro N, Todros T: Clinical significance of absent or reversed end diastolic velocity waveforms in umbilical artery. Lancet 1994;344:1664-1668.

21 Alfirevic Z, Stampalija T, Gyte GM: Fetal and umbilical Doppler ultrasound in high-risk pregnancies. Cochrane Database Syst Rev 2010;1:CD007529.
22 Morris RK, Malin G, Robson SC, Kleijnen J, Zamora J, Khan KS: Fetal umbilical artery Doppler to predict compromise of fetal/neonatal wellbeing in a high-risk population: systematic review and bivariate meta-analysis. Ultrasound Obstet Gynecol 2011;37:135-142.

23 Odibo AO, Goetzinger KR, Cahill AG, Odibo L, Macones GA: Combined sonographic testing index and prediction of adverse outcome in preterm fetal growth restriction. Am J Perinatol 2014;31:139-144.

24 Society for Maternal-Fetal Medicine Publications Committee, Berkley E, Chauhan SP, Abuhamad A: Doppler assessment of the fetus with intrauterine growth restriction. Am J Obstet Gynecol 2012;206:300-308.

25 Alfirevic Z, Stampalija T, Gyte GM: Fetal and umbilical Doppler ultrasound in normal pregnancy. Cochrane Database Syst Rev 2010; 8:CD001450.

26 American College of Obstetricians and Gynecologists: ACOG Practice bulletin no. 134: fetal growth restriction. Obstet Gynecol 2013; 121:1122-1133

27 De Paco C, Ventura W, Oliva R, Miguel M, Arteaga A, Nieto A, Delgado JL: Umbilical artery Doppler at 19 to 22 weeks of gestation in the prediction of adverse pregnancy outcomes. Prenat Diagn 2014;34:711-715.

28 Hadlock FP, Deter RL, Harrist RB, Park SK: Estimating fetal age: computer-assisted analysis of multiple fetal growth parameters. Radiology 1984;152:497-501.

29 Chauhan SP, Magann EF: Screening for fetal growth restriction. Clin Obstet Gynecol 2006; 49:284-294.

30 Bhide A, Acharya G, Bilardo CM, Brezinka C, Cafici D, Hernandez-Andrade E, Kalache K, Kingdom J, Kiserud T, Lee W, Lees C, Leung KY, Malinger G, Mari G, Prefumo F, Sepulveda $\mathrm{W}$, Trudinger B: ISUOG practice guidelines: use of Doppler ultrasonography in obstetrics. Ultrasound Obstet Gynecol 2013;41: 233-239.

31 Gotsch F, Cruciani L, Ghezzi F, Ogge G, Yeo L, Romero R: Doppler interrogation of the fetal circulation; in Fleischer AC, Toy EC, Lee W, Manning FA, Romero R (eds): Sonography in Obstetrics and Gynecology, ed 7. New York, McGraw Hill, 2011, pp 257-308.

32 Savchev S, Figueras F, Sanz-Cortes M, CruzLemini M, Triunfo S, Botet F, Gratacos E: Evaluation of an optimal gestational age cutoff for the definition of early- and late-onset fetal growth restriction. Fetal Diagn Ther 2014;36:99-105.

33 Figueras F, Gratacos E: Stage-based approach to the management of fetal growth restriction. Prenat Diagn 2014;34:655-659.

34 Crovetto F, Triunfo S, Crispi F, RodriguezSureda V, Roma E, Dominguez C, Gratacos E, Figueras F: First-trimester screening with specific algorithms for early- and late-onset fetal growth restriction. Ultrasound Obstet Gynecol 2016;48:340-348.
35 Alexander GR, Kogan MD, Himes JH: 19941996 U.S. singleton birth weight percentiles for gestational age by race, Hispanic origin, and gender. Matern Child Health J 1999;3: 225-231.

36 Stampalija T, Gyte GM, Alfirevic Z: Uteroplacental Doppler ultrasound for improving pregnancy outcome. Cochrane Database Syst Rev 2010;9:CD008363.

37 Albaiges G, Missfelder-Lobos H, Lees C, Parra M, Nicolaides KH: One-stage screening for pregnancy complications by color Doppler assessment of the uterine arteries at 23 weeks' gestation. Obstet Gynecol 2000;96:559-564.

38 Gomez O, Figueras F, Martinez JM, del Rio M, Palacio M, Eixarch E, Puerto B, Coll O, Cararach V, Vanrell JA: Sequential changes in uterine artery blood flow pattern between the first and second trimesters of gestation in relation to pregnancy outcome. Ultrasound $\mathrm{Ob}-$ stet Gynecol 2006;28:802-808.

39 Poon LC, Lesmes C, Gallo DM, Akolekar R Nicolaides KH: Prediction of small-for-gestational-age neonates: screening by biophysical and biochemical markers at 19-24 weeks. Ultrasound Obstet Gynecol 2015;46:437-445.

40 Triunfo S, Crovetto F, Rodriguez-Sureda V, Scazzocchio E, Crispi F, Dominguez C, Grata$\cos$ E, Figueras F: Changes in uterine artery Doppler velocimetry and circulating angiogenic factors in the first half of pregnancies delivering a small-for-gestational-age neonate. Ultrasound Obstet Gynecol 2017;49: 357-363.

41 Pardi G, Cetin I, Marconi AM, Lanfranchi A, Bozzetti P, Ferrazzi E, Buscaglia M, Battaglia FC: Diagnostic value of blood sampling in fetuses with growth retardation. $\mathrm{N}$ Engl J Med 1993;328:692-696.

42 Donner C, Vermeylen D, Kirkpatrick C, de Maertelaer V, Rodesch F: Management of the growth-restricted fetus: the role of noninvasive tests and fetal blood sampling. Obstet Gynecol 1995;85:965-970.

43 Marsal K: Intrauterine growth restriction. Curr Opin Obstet Gynecol 2002;14:127-135.

44 Williams KP, Farquharson DF, Bebbington M, Dansereau J, Galerneau F, Wilson RD, Shaw D, Kent N: Screening for fetal well-being in a high-risk pregnant population comparing the nonstress test with umbilical artery Doppler velocimetry: a randomized controlled clinical trial. Am J Obstet Gynecol 2003;188:1366-1371

45 Marsal K: Obstetric management of intrauterine growth restriction. Best Pract Res Clin Obstet Gynaecol 2009;23:857-870.

46 Story L, Sankaran S, Mullins E, Tan S, Russell G, Kumar S, Kyle P: Survival of pregnancies with small for gestational age detected before 24 weeks gestation. Eur J Obstet Gynecol Reprod Biol 2015;188:100-103. 
47 Turan OM, Turan S, Gungor S, Berg C, Moyano D, Gembruch U, Nicolaides KH, Harman CR, Baschat AA: Progression of Doppler abnormalities in intrauterine growth restriction. Ultrasound Obstet Gynecol 2008;32: 160-167.

48 Unterscheider J, Daly S, Geary MP, Kennelly MM, McAuliffe FM, O’Donoghue K, Hunter A, Morrison JJ, Burke G, Dicker P, Tully EC, Malone FD: Predictable progressive Doppler deterioration in IUGR: does it really exist? Am J Obstet Gynecol 2013;209:539.e1-e7.

49 Unterscheider J, Daly S, Geary MP, Kennelly MM, McAuliffe FM, O’Donoghue K, Hunter A, Morrison JJ, Burke G, Dicker P, Tully EC, Malone FD: Optimizing the definition of intrauterine growth restriction: the multicenter prospective PORTO Study. Am J Obstet Gynecol 2013;208:290.e1-e6.

50 Bahado-Singh RO, Kovanci E, Jeffres A, Oz U, Deren O, Copel J, Mari G: The Doppler cerebroplacental ratio and perinatal outcome in intrauterine growth restriction. Am J Obstet Gynecol 1999;180:750-756.

51 Odibo AO, Riddick C, Pare E, Stamilio DM, Macones GA: Cerebroplacental Doppler ratio and adverse perinatal outcomes in intrauterine growth restriction: evaluating the impact of using gestational age-specific reference values. J Ultrasound Med 2005;24:1223-1228.

52 DeVore GR: The importance of the cerebroplacental ratio in the evaluation of fetal wellbeing in SGA and AGA fetuses. Am J Obstet Gynecol 2015;213:5-15.

53 Figueras F, Gratacos E: Update on the diagnosis and classification of fetal growth restriction and proposal of a stage-based management protocol. Fetal Diagn Ther 2014;36:8698.

54 Morales-Rosello J, Khalil A, Morlando M, Papageorghiou A, Bhide A, Thilaganathan B Changes in fetal Doppler indices as a marker of failure to reach growth potential at term. Ultrasound Obstet Gynecol 2014;43:303-310.
55 Prior T, Paramasivam G, Bennett P, Kumar S: Are fetuses that fail to achieve their growth potential at increased risk of intrapartum compromise? Ultrasound Obstet Gynecol 2015;46:460-464.

56 Khalil AA, Morales-Rosello J, Elsaddig M, Khan N, Papageorghiou A, Bhide A, Thilaganathan B: The association between fetal Doppler and admission to neonatal unit at term. Am J Obstet Gynecol 2015;213:57.e1-e7.

57 Khalil A, Morales-Rosello J, Townsend R, Morlando M, Papageorghiou A, Bhide A, Thilaganathan B: Value of third-trimester cerebroplacental ratio and uterine artery Doppler indices as predictors of stillbirth and perinatal loss. Ultrasound Obstet Gynecol 2016;47:74-80

58 Triunfo S, Crispi F, Gratacos E, Figueras F: Prediction of delivery of small-for-gestational-age neonates and adverse perinatal outcome by fetoplacental Doppler at 37 weeks' gestation. Ultrasound Obstet Gynecol 2017; 49:364-371.

59 Khalil A, Thilaganathan B: Role of uteroplacental and fetal Doppler in identifying fetal growth restriction at term. Best Pract Res Clin Obstet Gynaecol 2017;38:38-47.

60 Flatley C, Greer RM, Kumar S: The magnitude of change in the fetal cerebroplacental ratio in the third trimester and the risk of adverse pregnancy outcome. Ultrasound Obstet Gynecol 2016, Epub ahead of print.

61 Bakalis S, Akolekar R, Gallo DM, Poon LC, Nicolaides KH: Umbilical and fetal middle cerebral artery Doppler at 30-34 weeks' gestation in the prediction of adverse perinatal out come. Ultrasound Obstet Gynecol 2015;45: 409-420.

62 Morales-Rosello J, Khalil A, Morlando M, Bhide A, Papageorghiou A, Thilaganathan B: Poor neonatal acid-base status in term fetuses with low cerebroplacental ratio. Ultrasound Obstet Gynecol 2015;45:156-161.

63 Warshak CR, Masters H, Regan J, DeFranco $\mathrm{E}$ : Doppler for growth restriction: the association between the cerebroplacental ratio and a reduced interval to delivery. J Perinatol 2015; 35:332-337.
64 Ropacka-Lesiak M, Korbelak T, Swider-Musielak J, Breborowicz G: Cerebroplacental ratio in prediction of adverse perinatal outcome and fetal heart rate disturbances in uncomplicated pregnancy at 40 weeks and beyond. Arch Med Sci 2015;11:142-148.

65 Akolekar R, Syngelaki A, Gallo DM, Poon LC, Nicolaides KH: Umbilical and fetal middle cerebral artery Doppler at 35-37 weeks' gestation in the prediction of adverse perinatal outcome. Ultrasound Obstet Gynecol 2015;46: 82-92.

66 Spinillo A, Gardella B, Bariselli S, Alfei A, Silini EM, Bello BD: Cerebroplacental Doppler ratio and placental histopathological features in pregnancies complicated by fetal growth restriction. J Perinat Med 2014;42:321-328.

67 Flood K, Unterscheider J, Daly S, Geary MP, Kennelly MM, McAuliffe FM, O'Donoghue K, Hunter A, Morrison JJ, Burke G, Dicker P, Tully EC, Malone FD: The role of brain sparing in the prediction of adverse outcomes in intrauterine growth restriction: results of the multicenter PORTO Study. Am J Obstet Gynecol 2014;211:288.e1-288.e5.

68 Monteith C, Flood K, Mullers S, Unterscheider J, Breathnach F, Daly S, Geary MP, Kennelly MM, McAuliffe FM, O’Donoghue K, Hunter A, Morrison JJ, Burke G, Dicker P, Tully EC, Malone FD: Evaluation of normalization of cerebroplacental ratio as a potential predictor for adverse outcome in SGA fetuses. Am J Obstet Gynecol 2017;216:285.e1-285. e6.

69 Espinoza J, Romero R, Nien JK, Gomez R, Kusanovic JP, Goncalves LF, Medina L, Edwin S, Hassan S, Carstens M, Gonzalez R: Identification of patients at risk for early onset and/or severe preeclampsia with the use of uterine artery Doppler velocimetry and placental growth factor. Am J Obstet Gynecol 2007;196: 326.e1-e13.

70 Romero R, Deter R: Should serial fetal biometry be used in all pregnancies? Lancet 2015; 386:2038-2040.
CPR $<$ th Percentile at 20-24 Weeks of Gestation and Fetal Size Later in Pregnancy
Fetal Diagn Ther 2018;44:112-123

DOI: $10.1159 / 000479684$ 